\title{
SAÚDE DA FAMÍLIA: DESAFIOS TEÓRICOS ${ }^{1}$
}

\author{
FAMILY HEALTH:THEORETICAL CHALLENGES \\ SALUD DE LA FAMILIA: DESAFIOS TEÓRICOS
}

Ingrid Elsen*

Coleta R. Althoff**

Gisele C. Manfrini*t*

RESUMO: Trata-se de um estudo reflexivo com a intenção de explorar as noções teóricas sobre família e saúde da família que emergem da literatura. Num primeiro momento, foram selecionadas as publicações sobre o Programa Saúde da Família. Os resultados indicam que o termo saúde da família é referido como uma estratégia e uma proposta de mudança no campo da saúde. Contudo, surge como um conjunto articulado de princípios, objetivos, crenças e práticas, que podem auxiliar na composição de um entendimento teórico sobre saúde da família. No segundo momento, são apresentados os conceitos de família, saúde da família e Enfermagem elaborados por um grupo que atua na área de família. A seguir, busca-se uma aproximação entre essas noções teóricas identificadas pelo estudo, finalizando com as sugestões para os avanços teóricos na formulação dos conceitos de família, saúde da família e Enfermagem à família.

DESCRITORES: Saúde da família; Família.

\section{INTRODUÇÃO}

Há algum tempo vem se falando sobre a saúde da família. Volta e meia os veículos de comunicação noticiam a implantação de mais uma unidade do Programa de Saúde da Família, em uma determinada cidade ou comunidade. Nos últimos tempos, os cidadãos brasileiros têm sido abordados em seus domicílios e questionados sobre suas famílias por membros das equipes de saúde. Ao mesmo tempo, o programa tem provocado nos profissionais um interesse em conhecer, aperfeiçoar e buscar uma qualificação na área. A saúde da família surge como algo "novo", impondo a necessidade de conhecê-la e entendê-la. Percebe-se um despertar para algo que está mudando a concepção do atendimento de saúde no país. Mas afinal, o que é saúde da família?

Estudiosos e profissionais de diferentes áreas de conhecimento, particularmente os da Enfermagem, têm revelado um interesse e buscado uma articulação entre a teoria e a prática em relação a saúde da família, no sentido de produzir e fortalecer o conhecimento.

Buscando-se a origem do termo, encontramos em Mauksch (1974), uma proposta para a concepção de saúde da família. Ele alerta para o fato de que os membros do grupo familiar se relacionam entre si, compondo uma família. Embora sejam interativas, a saúde do indivíduo é distinta da saúde da unidade familiar. J á Gilliss et al.(1989), refere que atribuir bem estar ou doença à unidade familiar é um fenômeno recente na literatura clínica, com exceção da psiquiatria, na qual o paciente é visto como sintoma de uma família com problemas. Barnhill apud Gilliss (1989), identificou como temas relacionados à saúde da família: processos de formação de identidade; mudança; processamento de informações e estruturação de papéis. De acordo com Gilliss et al. (1989), para avaliar a saúde da família, novas categorias evoluíram, tais como: comunicação, resposta às mudanças, reciprocidade e desempenho de papéis.

\footnotetext{
1 Trabalho apresentado no 53 Congresso Brasileiro de Enfermagem, 2001, Curitiba, PR.

* Enfermeira. Professora Titular da Universidade Federal de Santa Catarina. Doutora em Ciências da Enfermagem.

** Enfermeira. Professora Adjunto IV da Universidade Federal de Santa Catarina. Doutora em Filosofia em Enfermagem.

*** Acadêmica do Curso de Graduação em Enfermagem da UFSC. Bolsista de Iniciação Científica do CNPq.
} 
Em 1983, surgem na Enfermagem uma das primeiras publicações sobre o tema, destinada a estudantes de graduação e editada por Clements e Roberts em cujo título está explícito o termo saúde da família. Teorias de família e de Enfermagem são descritas e situações de cuidado de Enfermagem à famílias são apresentadas, a título de exemplificação. Embora não haja de forma explícita a definição do conceito saúde da família, percebese que em cada teoria, seu entendimento é coerente com os princípios e demais conceitos da mesma.

O Grupo de Assistência, Pesquisa e Educação na Área da Saúde da Família - GAPEFAM, ligado ao Programa de Pós-Graduação de Enfermagem da Universidade Federal de Santa Catarina vem, desde 1985, buscando a compreensão do que seja a saúde da família. Na elaboração de seu referencial teórico, o grupo optou por utilizar o conceito de família saudável. Outros autores, como Bomar (1990) e Nitschke et al. (1992), igualmente fazem menção a esse conceito família saudável. Todavia, não há um consenso e uma definição precisa do termo, assinalam Hanson e Boyd (1996). Nas leituras sobre o tema, são percebidos diferentes olhares, cada qual com seu ponto de vista e enfatizando algumas dimensões.

A abrangência do tema tem nos desafiado a pensar, conduzindo-nos a refletir acerca das suas concepções teóricas. Considerando o objeto de interesse para a reflexão, o presente estudo objetiva: explorar as noções teóricas sobre o tema e oferecer uma contribuição para a construção teórica sobre saúde da família.

\section{CONSTRUINDO O CAMINHO PARA A REFLEXÃO}

Instigadas pela curiosidade e com a finalidade de conhecer qual é a idéia de saúde da família quando se fala sobre esse tema, decidimos, inicialmente, realizar a reflexão a partir da análise da literatura tendo como base a seguinte questão norteadora: Quais são as noções sobre saúde da família que emergem sobre o tema? Entre as publicações realizadas nos últimos anos, optamos por considerar os artigos da Revista Brasileira de Saúde da Família e Relatório Final do I Seminário de Experiências Internacionais em Saúde da Família, publicações do Ministério da Saúde, e pela R evista Brasileira de Enfermagem, número especial sobre a Saúde da Família, uma vez que essas publicações trazem informações e relatam as experiências dos profissionais que atuam na área. U m instrumento foi construído e avaliado com a finalidade de possibilitar o levantamento e a análise dos dados, obtidos em 56 artigos publicados nas revistas. Os procedimentos realizados nos ofereceram subsídios para entender o que é o Programa Saúde da Família e algumas noções teóricas sobre saúde, família e saúde da família.

A pós a realização do primeiro momento do estudo, decidimos fazer uma consulta ao referencial teórico do GAPEFAM, tendo em vista que esse grupo tem uma experiência no desenvolvimento de conceitos e participação na produção de conhecimento sobre a família. A seguir, partimos para o terceiro momento no qual se busca uma aproximação entre as noções teóricas presentes na literatura e as elaboradas pelo grupo.

\section{SAÚDE DA FAMÍLIA: O PONTO DE VISTA TEÓRICO DE UM PROGRAMA}

O conjunto de idéias teóricas agrupadas e interconectadas possibilita a formulação de noções sobre um determinado fenômeno, de modo que possamos entendê-lo. Nestes tempos, surge a necessidade de compreender o que é a saúde da família, quais são as idéias fundamentais que a caracterizam como fenômeno, e como é concebida ou referida.

Para dar início a reflexão, as noções sobre a concepção do Programa Saúde da Família (PSF) lançado pelo Ministério da Saúde e as experiências dos profissionais que têm participado na sua implantação, constituíram o foco de análise. Com o desenvolvimento do processo analítico dos artigos publicados, identificou-se quatro unidades de análise assim definidas: modo de referir, conjunto articulado, proposta de mudança e noções conceituais. Essas unidades de análise revelam como o PSF é compreendido pelos autores dos artigos.

Inicialmente, ao realizar as leituras dos artigos, por vezes, percebíamos que os próprios autores ficavam confusos ao definir o que é o PSF. Algumas vezes, o termo era citado como um programa, outras vezes, como estratégia, sistema ou modelo de atenção à saúde. Ao considerarmos importante estas informações, resolvemos agrupá-las em uma unidade que denominamos modo de referir, enfatizando as idéias lançadas como estratégia e como instrumento para se buscar eqüidade na saúde. 
A estratégia, segundo o dicionário Michaelis (1998, p.901), é a arte de dirigir coisas complexas. Quando se fala no PSF como uma estratégia, constata-se que os autores fazem referência a ele como a reorganização do modelo assistencial. Souza (1999), em seu artigo declara que o PSF propõe uma nova dinâmica para a estruturação dos serviços de saúde, bem como para sua relação com a comunidade e entre os diversos níveis de complexidade assistencial. Essa estratégia é vista também como uma mudança no modo de conduzir a saúde no país, como revela a seguinte declaração: "O PSF deve ser a porta de entrada do sistema local de saúde e a mudança do modelo tradicional" (Souza, R., 1999). 0 modelo vigente não tem dado conta das questões relacionadas ao sistema de saúde. Essa nova proposta surge como uma alternativa para enfrentar os problemas. F ranco e Rocha (2000, p. 27), cita a declaração feita por um médico, na qual declara que "à medida que o trabalho vai se desenvolvendo, observa-se a necessidade de encontrar cada vez mais esses laços, (...) uma vez que os problemas de saúde são enfrentados e resolvidos em parceria com a comunidade e profissionais em território já definido". Há autores que vão mais além, eles indicam o redirecionamento do modelo, com uma nova visão para o atendimento em saúde. Franklin (1999, p. 46), ressalta que "a saúde da família mexe com todos os paradigmas até hoje existentes, então é uma coisa nova".

0 modelo ainda presente em nossas instituições não tem favorecido a saúde para todos, objeto de compromissos estabelecidos entre as organizações de saúde. Desse modo, o PSF é compreendido como um instrumento para se buscar a eqüidade. Montenegro et al. (2000, p. 27), declara que "a idéia não era em nenhum momento oferecer um programa "pobre" para uma população pobre. Pelo contrário (...) onde as carências eram maiores deveriam ser concentrados os melhores recursos." Embora os relatos revelem experiências realizadas em comunidades carentes, a idéia é possibilitar que as pessoas dessas comunidades sejam engajadas no sistema. Percebe-se que o PSF é uma alternativa para enfrentar os problemas do $S$ istema Único de Saúde, concebido como estratégia para a atenção básica, numa proposta de mudança do modelo.

Na segunda unidade de análise, o PSF é visto como um conjunto articulado de princípios, crenças, objetivos, práticas e saberes. Ao se considerar princípio como aquilo que governa as ações, constata-se que 0 PSF está integrado aos princípios do Sistema Único de Saúde. Eles visam a eqüidade, a democratização do acesso, a assistência para todos de maneira integral, equânime, contínua e resolutiva em todos os níveis de complexidade. Dessa maneira, o programa objetiva substituir as práticas tradicionais, possibilitar regionalização e hierarquização do atendimento e desenvolver um trabalho voltado para a realidade dos grupos sociais. Com isso busca-se uma integração entre a família, comunidade e o sistema de saúde para a identificação dos fatores de risco e a manutenção da vigilância epidemiológica com a finalidade de oferecer melhores condições e qualidade de vida.

As crenças estão voltadas para o resgate dos valores profissionais, dando importância para a humanização, a arte de atender o ser humano considerando as suas particularidades e seu contexto. Sousa (2000, p.25), declara que ao se propor a humanização de práticas de saúde, busca-se "a satisfação do usuário através do estreito relacionamento dos profissionais com a comunidade". Cunha (1999, p.35), ao relatar uma experiência na implantação do programa ressalta a fala de um dos integrantes da equipe "A grande mudança a que realmente importa, está na forma de atender, de conversar com as pessoas".

Com base nos princípios e crenças, as práticas são estimuladas para serem desenvolvidas por uma equipe multiprofissional para trabalhar em um território definido. Essa prática caracteriza-se pela entrada dos profissionais nos domicílios das famílias. É uma prática com inserção na comunidade, buscando formar vínculos de compromissos, responsabilidades compartilhadas e desenvolvimento de parcerias com a população. Confirmando esta idéia, J osé Serra (2000, p.3), Ministro da Saúde, declara que o PSF tem "o objetivo de organizar as ações de saúde perto de cada família, onde os membros da comunidade possam participar e ajudar a resolver seus próprios problemas. A isso chamamos de vínculos de compromisso e de coresponsabilidade entre a equipe e a população".

Além de uma mudança no desenvolvimento de ações de saúde, o programa propõe uma interligação com as instituições de ensino, propondo modificações nos currículos para a formação dos novos profissionais e a capacitação constante dos que integram as equipes. A avaliação do programa e a estimulação de investigações na área são incentivados nas articulações no sentido de se construir e ampliar o conhecimento. Esse conjunto articulado de princípios, crenças, práticas e saberes conduz a um modo de pensar, ser e fazer o PSF. 
A terceira unidade de análise revela que o PSF é percebido como uma proposta de mudança em relação ao foco de atenção, a postura profissional, a estrutura de ação e a prática dos profissionais. Durante muitos anos, o sistema de saúde vem focalizando a sua atenção no indivíduo, cujas particularidades têm sido atendidas pelas diversas especialidades.

Ao se considerar o foco de atenção, percebe-se que o PSF procura centralizar a atenção ao ser humano como cidadão, membro de uma família, que vive em um determinado espaço geográfico e domiciliar. 0 programa volta-se para uma mudança na sua estrutura de ação. Ele propõe a construção de laços entre os membros que formam a equipe, entre ela a família e a comunidade, assim como a formação de parcerias entre os serviços de saúde e entre as instituições de ensino. Dentro de uma perspectiva mais ampla, propõe-se a interligação entre os governos municipal, estadual e federal, como gestores para a viabilização do programa. A proposta de mudança está dirigida para os profissionais, tanto para a mudança na postura quanto para a prática profissional. Em relação à postura, verifica-se a presença de vínculos mais fortalecidos entre o profissional e o cliente, registrado na seguinte declaração "A medida que o trabalho vai se desenvolvendo observa-se a necessidade de encurtar cada vez mais esses laços, e isso ocorre naturalmente, uma vez que os problemas de saúde são enfrentados e resolvidos em parceria com essa comunidade e profissionais" (Franco e Rocha 2000, p.24). 0 trabalho passa a ser desenvolvido em equipe com enfoque multidisciplinar. Quando necessário, a equipe vai em busca de um suporte com outros profissionais. A prática, por sua vez, torna-se mais humanizada. Muda também o local de atuação, que passa a ser o domicílio e a comunidade. A metodologia de atendimento é construída em parceria com a família e membros da comunidade e também na utilização de outras técnicas, especialmente as de educação em saúde, que vão sendo incorporadas à prática.

Um programa de saúde não pode ser visto apenas na composição explícita de sua proposta, mas a partir de sua abrangência teórica que implicitamente constitui o seu fundamento. A quarta unidade de análise está relacionada às noções conceituais sobre saúde e saúde da família que emergem dos artigos estudados. A saúde na maioria das vezes, é referida como qualidade de vida, como revelam as seguintes declarações: "Saúde passa a ser entendida de forma bem diferente: como qualidade de vida" (Franklin, 1999, p.43). "A equipe do PSF me fez entender que precisava melhorar minha qualidade de vida" (Cáceres, 2000, p.18).

A qualidade de vida como referência parece estar relacionada a uma visão mais ampla de saúde como podemos observar pelas seguintes declarações: "Todo mundo sabe que saúde rima com qualidade de vida. Por isso, sentir-se saudável, mais que um conceito biológico, envolve dimensões psicológicas, afetivas e de auto-estima" (Cáceres, 2000, p.18). Saúde envolve "questões relativas à área econômica, social e até mesmo psicológica" (Montenegro et al, 2000, p.27).

O impacto do PSF na qualidade de vida da população está relacionado aos dados sobre a redução da mortalidade infantil, diminuição das taxas de internação hospitalar e consumo de medicamentos e outros indicadores quantitativos, mas também com a redução de estresse. Contudo, a utilização dos indicadores para avaliar as condições de saúde da população, traduzem a noção de saúde como ausência de doença. "Depois que começamos o trabalho (...) diminuíram as complicações diabéticas" (F ranklin, 1999, p.54). Nesse plano de análise, percebe-se que a saúde é expressa tanto sob um ponto de vista ideológico, como pragmático.

Quanto a saúde da família, antes de apresentar sua concepção devemos fazer referência à compreensão de família, uma vez que essa não pode estar desvinculada do entendimento de saúde da família. Nas publicações analisadas, a família é referida como "um importante espaço das relações sociais desenvolvendo funções importantes como a produção da espécie, criação ou socialização dos filhos e a transmissão do patrimônio cultural" (Montenegro et al., 2000, p.27). A família é também percebida como espaço social e núcleo básico da abordagem (Souza,1999). Neste sentido, como membro de uma comunidade inserida em um espaço geográfico e social, a família é considerada como o eixo norteador das ações de saúde.

É importante registrar que a compreensão de família segue com o acréscimo de novas visões, a medida que novas experiências de trabalho vêm sendo apresentadas. Quando se analisa as publicações mais recentes, percebe-se uma mudança por parte dos profissionais em relação a idéia de família. Ela passa a ser considerada como uma estrutura formada por seus membros cujas relações conduzem um modo de viver próprio. Também é percebida como um sistema que enfrenta crises, se desestrutura quando tem dificuldades, necessitando de suporte para enfrentar as situações. Neste contexto, a família é compreendida como parceira nas ações dos profissionais e cuidadora nas situações de doença e promotora de saúde. 
E mbora a idéia central do programa seja a saúde da família, o seu conceito não surge claramente formulado. Os autores ao discorrerem sobre a saúde da família, lançam algumas idéias. Percebe-se que com a mudança do modelo, o indivíduo não é mais visto isoladamente, mas como membro de uma família, como declaram Montenegro et al. (2000, p.29), "passamos a ver o indivíduo como um "todo" integrado ao seio de uma família e vivendo sonhos, desejos e tendo vontade própria". Por outro lado, a saúde da família é vista como "aquilo que os sujeitos sociais, nos seus espaços de trabalho, nos seus espaços de vida, conseguem confrontar, entre outros projetos distintos que disputam, esse espaço social" (Paim, 1999, p.31).

0 que surge de novo na proposta é a idéia de considerar a família como parceira da equipe no desenvolvimento de ações, visando a saúde do indivíduo. Serra (1999, p.5), declara que "Quem fala de Saúde da Família, fala em ações combinadas e está pensando a partir da noção ampliada de saúde, que engloba tudo aquilo que pode levar a pessoa a ser mais feliz e produtiva". Percebe-se que a família é considerada como cuidadora nas situações de doença de seus membros e um espaço onde se constrói saúde. Desse modo, entendemos que a idéia sobre saúde da família está centrada na saúde dos membros da família.

\section{APONTANDO AS NOÇÕES CONCEITUAIS RELATIVAS À SAÚDE DA FAMÍLIA E ENFERMAGEM DESENVOLVIDAS POR UM GRUPO DE ESTUDOS}

Segundo Meleis (1997), todas as disciplinas se organizam em torno de um domínio de conhecimentos que se apresenta como um território com limites teóricos e práticos. Entre os aspectos que caracterizam um domínio esta autora aponta a definição de conceitos básicos; o reconhecimento e a utilização de diferentes paradigmas pelos membros de cada disciplina e a existência de experiências acumuladas ao longo do tempo, as quais são submetidas à análise e crítica, segundo critérios aceitos pela comunidade científica.

No que se refere ao domínio da Enfermagem foram inicialmente reconhecidos como conceitos básicos: pessoa, sociedade, saúde e Enfermagem. Com o decorrer dos anos alguns foram modificados, enquanto outros acrescidos. Em 1987, S chult女 argumentou que o cliente da Enfermagem deveria incluir, além da pessoa, ser humano, a pluralidade de pessoas tais como família, grupo, comunidade. Meleis (1997), ainda identifica como conceitos centrais, além dos já citados: interação, ambiente e transição.

O GAPEFAM ao definir seu referencial teórico, adotou os seguintes conceitos: família, família saudável, Enfermagem à família e assistência à família. Mais tarde, em decorrência de um estudo analítico realizado por Penna (1992), foi acrescido o conceito de ambiente, e em seguida, o de processo de viver da família, cidadania e interdisciplinaridade.

No presente estudo julgamos importante apresentar as noções teóricas referentes à família, família saudável e enfermagem à família (Elsen et al., 1992), adotadas pelo grupo a fim de subsidiar as reflexões e a busca de respostas para os vazios identificados quanto aos conceitos apresentados no primeiro momento do estudo.

Família: é uma unidade dinâmica, com uma identidade que lhe é peculiar, constituída por seres humanos unidos por laços de sangue, de interesse e/ou afetividade, que se percebem como família, que convivem por um espaço de tempo construindo uma história de vida. Os membros da família possuem, criam e transmitem crenças, valores, conhecimentos e práticas de saúde, têm direitos e responsabilidades, desenvolvendo uma estrutura e uma organização própria. Estabelecem objetivos de vida e interagem entre si e com outras pessoas e grupos, em diferentes níveis de aproximação. A família está inserida em um determinado contexto físico, sócio cultural e político, influenciando e sendo por ele influenciado.

Família saudável: é uma unidade que se auto-estima positivamente, onde seus membros convivem e se percebem mutuamente como família, tendo uma estrutura e organização flexível para definir objetivos e prover os meios para o crescimento, desenvolvimento, a saúde e o bem estar de seus membros. A família saudável se une por laços de afetividade, exteriorizados por amor e carinho, seus membros têm liberdade de expor sentimentos e dúvidas. A família saudável compartilha crenças, valores, conhecimentos e práticas, aceita a individualidade de seus membros, conhece e usufrui de seus direitos, enfrenta crises, conflitos e contradições, pedindo e dando apoio a seus membros e às pessoas significativas. Além disso, atua conscientemente no ambiente em que vive, interagindo dinamicamente com outras pessoas e famílias em diversos níveis de 
aproximação, transformando e sendo transformada. A família e seus membros desenvolvem-se com as experiências, construindo sua história de vida.

Enfermagem à família: consiste no desenvolvimento de reflexões, decisões e ações, em que ambas, Enfermagem e família, em um processo participativo de ensino-aprendizagem, buscam conhecer-se mutuamente, definindo situações da vida familiar, compartilhando conhecimentos, crenças e valores e negociando meios para agirem nas situações, a fim de prover mudanças conscientes em seu processo de viver para que este ocorra de forma mais saudável.

A Enfermagem ao comprometer-se com a família como unidade a ser cuidada focaliza sua atenção nas interações intra e extra-familiares, busca conhecer o processo de viver da família, as transições e crises que enfrentam, identificando suas fragilidades, fontes de estresse, recursos e seus modos de cuidar. Entre as ações terapêuticas que a Enfermagem desenvolve com a família foram identificadas: reconhecimento da família como sujeito do seu processo de viver e se cuidar, com direitos e responsabilidades; o ouvir atentamente; ser sensível, estar presente, comprometer-se, lutar, respeitar e garantir os direitos da família; incentivar o cuidado familial; trabalhar em sintonia com outros profissionais e buscar o aperfeiçoamento pessoal e profissional, entre outros.

\section{APONTANDO ALGUMAS POSSIBILIDADES DE ARTICULAÇÕES TEÓRICAS}

Neste momento, apresentamos algumas aproximações teóricas possíveis elaboradas a partir das noções identificadas na pesquisa bibliográfica, e os conceitos desenvolvidos pelos membros do GAPEFAM. Nos parece de extrema relevância a retomada do conceito de saúde, tendo em vista ser o mesmo, parte do domínio da disciplina de enfermagem. A reflexão sobre os dados que emergiram do estudo, nos apontam que a saúde contém, no mínimo, três dimensões: do viver; do objetivo/subjetivo e a dos direitos e deveres; dimensões estas que, embora diferentes, se interpenetram, mostrada na figura 1.

FIGURA 1 - DIMENSÕES DO CONCEITO SAÚDE.

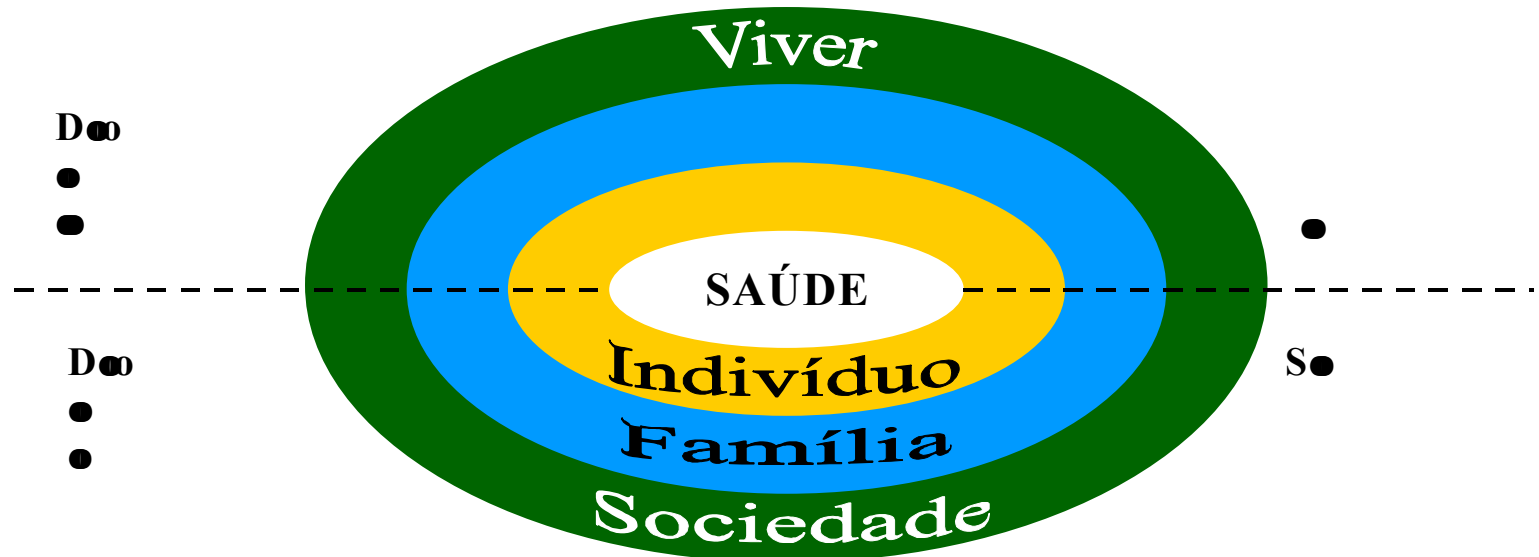

Ao referir-se a saúde, os autores das publicações analisadas fazem menção à saúde do viver individual e coletivo. Sabe-se, contudo, que além destas, há a saúde de grupos e entre esses, a da família. Embora exista a necessidade de aprofundar o significado de cada uma delas, na prática assistencial constata-se que elas se encontram interrelacionadas (Elsen, 1994).

A saúde ainda é percebida pelas pessoas e grupos através de dados objetivos e subjetivos, que muitas vezes, se confundem com o "ter" e o "ser". No primeiro momento desse estudo, os autores dos artigos fazem referência ao ter moradia, ter salário, ter educação, enquanto no segundo surgem o: sentir-se bem, ter disposição, poder trabalhar, lutar por seus direitos. 
A dimensão dos direitos e deveres vinculados à saúde de indivíduos, famílias e comunidade são citados em vários trabalhos. Neste sentido, talvez uma das características mais salientes está relacionada ao cuidado de si (individual), ao cuidado familial (prestado pela família) e o cuidado da coletividade, responsabilidades tanto individual, grupal como do próprio Estado. Por outro lado, a consciência dos direitos dos indivíduos, da família e da própria comunidade nem sempre são ressaltadas e ou garantidas nos serviços de saúde (Boehs, 2001). O bserva-se, no entanto, um movimento do SUS e do P rograma de Saúde da Família em direção à maior participação das pessoas e comunidades nas decisões sobre políticas e programas voltados à saúde.

Dentro desta perspectiva multidimensional de saúde, a saúde da família surge como possibilidade distinta da saúde de seus membros, como um processo que se dá nas inter-relações complexas entre seus membros, entre a família e sua rede social, a família e a comunidade, a família e a equipe de saúde e entre a família e a sociedade. No decorrer do viver em família, no dia a dia, alguns indicadores que sinalizam a saúde da família, dizem respeito ao mundo interior da família como:

- uma organização interna flexível para atender às necessidades de seus integrantes;

- respeito à individualidade de seus membros;

- estímulo ao diálogo;

- a existência, compartilhamento, transmissão e recriação de valores, crenças, conhecimentos e práticas;

- busca de um crescimento e desenvolvimento saudável de seus membros;

- o cuidado a seus membros na saúde e na doença.

Como indicadores externos da saúde da família estão incluídos os que demonstram sua inserção ativa na comunidade, como:

- interação dinâmica com outras famílias e comunidade;

- exercício do controle social;

- busca de melhores condições de vida através de movimentos organizados da sociedade;

- participação consciente nos programas de saúde.

Entre as diversas possibilidades para se repensar a família está a de considerá-la como um espaço interacional singular no qual estão presentes relações de poder, gênero e intergeracionais, que tem uma cultura própria embasando suas práticas cotidianas e que constrói sua história de vida. Além disso, a família se apresenta sob uma diversidade de configurações (nuclear, extensa, monoparental, a dotiva, entre outras.), corroborando a afirmação de Kaloustian (1994), ao declarar que o termo "famílias" era mais adequado à realidade atual do que família, no singular.

Finalmente, para se pensar um conceito de Enfermagem à família, as reflexões sobre os diferentes momentos deste estudo nos conduzem a três grandes eixos/ações: as voltadas à família, à sociedade e ao desenvolvimento do conhecimento sobre saúde e família.

A Enfermagem assume a família como foco do cuidado profissional quando: reconhece e respeita as diferentes formas de viver e conviver das famílias; busca fortalecer as famílias no cuidado a seus membros; reflete com as famílias sobre a qualidade do seu viver; compartilha saberes aproximando o cuidado familiar e profissional; apoia e estimula os recursos internos e externos da família.

A Enfermagem, e as famílias, são consideradas partes integrantes de um contexto físico, sócio/cultural, mas também possuem capacidades que podem através de movimentos organizados, produzir mudanças para um melhor viver. Neste sentido, a Enfermagem atua quando: garante e defende os direitos da família nos serviços de saúde; estimula a participação e o controle social; incentiva a democratização das relações interpessoais nos serviços; participa na elaboração e implementação de políticas e programas visando a saúde e o bem estar das famílias.

As ações relacionadas com o desenvolvimento do conhecimento incluem a utilização, avaliação e divulgação de conceitos e/ou referenciais teóricos e metodologias no atendimento à família, assim como estudos sobre trabalhos interdisciplinares com famílias. 


\section{CONSIDERAÇÕES FINAIS}

Apesar da família ser considerada cliente da Enfermagem desde o surgimento da mesma como profissão, constata-se ainda um grande vazio no que se refere ao entendimento do que seja família, saúde da família e Enfermagem à família. Neste trabalho procuramos oferecer subsídios para ampliar a discussão sobre estes conceitos que fazem parte do domínio da Enfermagem como disciplina. Todavia, é preciso prosseguir os estudos sobre a temática, através de pesquisas bibliográficas mais abrangentes, estudos com famílias e com os profissionais que trabalham com famílias, utilizando diferentes metodologias de investigação a fim de que se possa aprofundar o conhecimento sobre a mesma. J ulgamos ainda promissor a continuidade sobre o que seja família saudável e saúde da família, buscando-se a distinção entre ambos, se for o caso. Por fim, a busca de indicadores positivos de saúde da família, surge como uma possibilidade que merece ser analisada em estudos futuros.

ABSTRACT: This is a reflexive study which aims at exploring the theoretical notions about family and family health that emerge from the literature. At first, the publications about the Family Health Program were selected. The results suggest that the term family health is referred as a strategy and as a proposal of change in the field of health care. However, it arises as an articulated group of principles, objectives, beliefs and practices that may aid in the formation of a theoretical understanding about family health. Secondly, the concepts of family, family health and nursing elaborated by a group that works in the area presented. After that, an approximation between those concepts and the theoretical notions identified by the study is sought. At last, the work is concluded with suggestions for the theoretical advance in the formulation of concepts of family, family health and family nursing.

KEY WORDS: F amily health; F amily.

RESUMEN: Se trata de un estudio reflexivo com la intención de explorar las nociones teóricas sobre la familia que surgen en la literatura. Inicialmente, fueron seleccionadas las publicaciones sobre el programa « saúde da família». Los resultados indican que el término salud de la familia se refiere a una estrategia y a una propuesta de cambios en el campo de la salud. Sin embargo, surge como un conjunto articulado de principios, objetivos, creencias y prácticas que pueden auxiliar en la composición de un entendimiento teórico sobre la salud de la familia. Enseguida, son presentados los conceptos de familia, salud de la familia y enfermería, elaborados por un grupo que actúa en el área de la familia. A seguir, se busca una aproximación entre las nociones teóricas identificadas por el estudio, finalizando con las sugestiones para el avance teórico en la formulación de los conceptos de familia, salud de la familia y enfermería a la familia.

PALABRAS CLAVE: Salud de la familia; Familia.

\section{REFERÊNCIAS}

1 BOEHS, A. E. Os movimentos de aproximação e distanciamento entre os sistemas de cuidado familiar e profissional. Florianópolis: UFSC, 2001. 267p. Tese (Doutorado em Filosofia em Enfermagem) - Universidade Federal de Santa Catarina.

2 BOMAR, P. J. Perspectives on family health promotion. Family Community Health, Rockville, v. 12, n. 4, p. 1-11, 1990.

3 CÁCERES, L. S. Piraju: Aposta na alegria e na solidariedade. Revista Brasileira de Saúde da Família, Brasília, v. 1, n. 3, p. 14-19, dez. 2000.

4 CLEMENTS, I. W. ; ROBERTS, F. B. Family health: a theoretical approach to nursinf care. New York: J ohn Wiley \& Sons, 1983.

5 CUNHA, J. P. M. 0 amor faz a diferença. Revista Brasileira de Saúde da Família, Brasília, v. 1, p. 30-29, nov. 1999.

6 ELSEN, l. et al. Um marco conceitual para o trabalho com famílias. Florianópolis: GAPEFAM/UFSC, 1992. Mimeografado.

7 ELSEN, I. Desafios da enfermagem no cuidado de famílias. In: BUB, I. R. et al. (Org.). Marcos para a prática de enfermagem com famílias. Florianópolis: UFSC, 1994. p. 61-77.

8 FRANCO, S. E. G.; ROCHA, K. B. Chapadão do Céu: Uma equipe faz a diferença. Revista Brasileira de Saúde da Família, Brasília, v. 1, n.3, p. 20-25, dez. 2000. 
9 FRANKLIN, A. S. Com vontade de sobra e muita garra. Revista Brasileira de Saúde da Família, Brasília, v. 1, p.40-47, nov.1999.

10 FRANKLIN, A. V. T. Alicerçando no PSF a reforma do Sistema de Saúde. Revista Brasileira de Saúde da Família, Brasília, v. 1, p. 48-57, nov. 1999.

11 GILLISS, C. L. et. al.. Toward a science of family nursing. Los Angeles: Addison - Wesley, 1989.

12 HANSON, S. M. H; BOYD, S. T. Family health care nursing: theory, practice, and research. Philadelphia: F. A. Davis, 1996.

13 KALOUSTIAN, S. M. Família brasileira: a base de tudo. São Paulo: Cortez, Brasília, 1994.

14 MAUKSCH, H. D. A social science basis for conceptualizing family health. Social Science and Medicine, 0xford, v. 8, n. $9 / 10$, p. 521-528, 1974.

15 MELEIS, A. I. Theoretical nursing: development and progress. 3. ed. Philadelphia: Lippincott, 1997.

16 MICHAELIS moderno dicionário da língua portuguesa. São Paulo: Companhia Melhoramentos, 1998.

17 MONTENEGRO, J. V. S. et al. Vitória: 0 destino tomado nas mãos. Revista Brasileira de Saúde da Família, Brasília, v. 1, n. 3, p. 26-31, dez.2000.

18 NITSCHKE, R. G. et al. Família saudável: uma reflexão sobre o conceito e sua aplicabilidade na assistência. Florianópolis: Texto Contexto Enf., v. 1, n. 2, p. 152-166, 1992.

19 PAIM, J . O Programa de Saúde da Família no contexto do Sistema Ú nico de Saúde - Debatedor. I Seminário de Experiências Internacionais em Saúde da Família. Relatório Final. Brasília, Ministério da Saúde, 1999. p. 31-32.

20 PENNA, C. M. M. Repensando o pensar: análise crítica de um referencial teórico de enfermagem à família. Florianópolis: UFSC, 1992. Dissertação (Mestrado em Enfermagem) - Curso de Mestrado em Assistência de Enfermagem, Universidade Federal de Santa Catarina.

21 SEMINÁRIO DE EXPERIÊNCIAS INTERNACIONAIS EM SAÚDE DA FAMÍLIA, v. 1, 1999, Brasília. Relatório Final. Brasília: Ministério da Saúde, 1999.

22 SCHULTZ, P. Whem client means more than one: extending the foundational concept of person. Adv. Nurs. Sci., v. 10, n.1, p. 71-86, 1987.

23 SERRA, J. A diversidade é a maior riqueza. Revista Brasileira de Saúde da Família, Brasília, v.1, p. 5-6, nov. 1999.

24 SERRA, J. Gente que cuida de gente. Revista Brasileira de Saúde da Família, Brasília, v. 1, n. 3, p.3, dez. 2000.

25 SOUSA, M. F. de. A enfermagem reconstruindo sua prática: mais que uma conquista no PSF. Rev. Bras. Enferm., Brasília, n. esp., p. 25-30, dez. 2000.

26 SOUZA, H. M. de. O Programa de Saúde da Família no contexto do Sistema Único de Saúde. In: Seminário de Experiências Internacionais em Saúde da Família. Relatório Final. Brasília: Ministério da Saúde, p. 24-26, 1999.

27 SOUZA, H. M. de. 0 futuro tecido no presente. Revista Brasileira de Saúde da Família. Brasília: Ministério da Saúde, n. 1, p. 7-9, 1999.

28 SOUZA, R. R. A população em primeiro lugar. Revista Brasileira de Saúde da Família, Brasília, v. 1, p.4, nov.1999. 